\title{
Sacrococcygeal Teratoma - An Interesting Case and Infrequently seen Extension in Spinal Cord
}

\section{Deepak Sharma*, Srinivas Murki and Tejo Pratap}

Department of Neonatology, Fernandez Hospital, Hyderabad, India

*Corresponding author: Deepak Sharma, Department of Neonatology, Fernandez Hospital, Hyderabad, India, Tel: +33 491385517 ; Fax: +33 491387772 ; E-mail: dr.deepak.rohtak@gmail.com

Received date: February 21, 2017; Accepted date: April 08, 2017; Published date: April 29, 2017

Copyright: @ 2017 Sharma D, et al. This is an open-access article distributed under the terms of the Creative Commons Attribution License, which permits unrestricted use, distribution, and reproduction in any medium, provided the original author and source are credited.

\begin{abstract}
A male baby of $2.6 \mathrm{~kg}$ was born to Gravida2Para0Abortion1 mother through normal vaginal delivery at 33 weeks of gestation. Baby had normal Apgar score of $8 / 9 / 9$ at one, five and ten minutes respectively. At birth baby was noticed to have large swelling in the sacrococcygeal region which was approximately having the size of $10^{\star} 2 \mathrm{~cm}$, with solid consistency and erythematous.
\end{abstract}

Keywords: Sacrococcygeal teratoma; Kidney

\section{Introduction}

Teratomas are most common neonatal tumour and consist of tissues that arise from embryonic ectoderm, mesoderm and endoderm. The word teratoma is derived from Greek words teratos/teras, meaning "monster," and onkoma/oma, denoting a swelling, tumour or neoplasm. It is a true tumour or neoplasm and consists of multiple tissues of different kinds and these tissues are foreign to the parts in which they arise. The common locations of teratomas in pediatric population are sacrococcygeal, gonadal, mediastinal, and retroperitoneal [1]. Here we report a new-born having sacrococcygeal teratoma with rare intraspinal extension.

\section{Case}

A male baby of $2.6 \mathrm{~kg}$ was born to Gravida2Para0Abortion 1 mother through normal vaginal delivery at 33 weeks of gestation. Baby had normal Apgar score of 8/9/9 at one, five and ten minutes respectively. At birth baby was noticed to have large swelling in the sacrococcygeal region which was approximately having the size of $10^{\star} 12 \mathrm{~cm}$, with solid consistency and erythematous (Figures 1 and 2). There was scrotal skin thickening with hydrocele and anal opening was present in centre of the mass. There was differential edema with only right lower limb having pitting edema. Detailed physical examination showed slight retrognathia with no other malformation. Ultrasonography of the abdomen showed minimal ascites, distended urinary bladder, bilateral enlarged kidney with moderate hydronephrosis, heterogonous swelling with cystic solid area with measurement of approximately 7.9 $\mathrm{cm}^{\star} 8.1 \mathrm{~cm}$ with vascularity on colour Doppler. MRI done showed enhancing heterogonous density lesion with area of calcification, fat attenuation and cystic component in presacral region with internal and external component. Internal component extended into lower abdomen with intraspinal extension in sacral region, with features suggesting type 3 Sacrococcygeal teratoma (Figure 3). Echo and cranial ultra-sonogram done showed no malformations. The infant parents shifted the infant to other hospital where the infant died because of neonatal sepsis without undergoing any surgery.

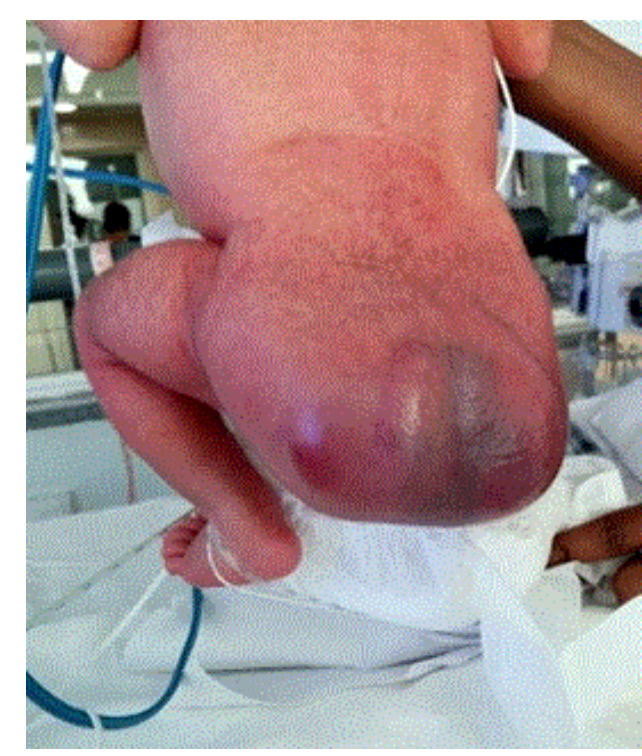

Figure 1: Figure showing swelling (mass) in Sacrococcygeal region which is about the size of $10 \times 12 \mathrm{~cm}$, solid and erythematous.

\section{Discussion}

Teratomas are most common neonatal tumour that can originate anywhere in the body but the most common site of origin is the Sacrococcygeal region. The estimated incidence range from $1 / 35000$ to $1 / 40000$ live births. It has sex predilection with female affected more than male with ratio being 4:1 [1]. These tumours contain cell lineage from all three cell lines, i.e., endoderm, mesoderm and ectoderm. They are believed to originate from the totipotent cells of Hensen's node $[2,3]$. These tumours can be both benign and malignant in nature. Sacrococcygeal teratoma (SCT) is the most common germ cell tumor (GCT) of childhood and fetus, with an estimated incidence of 1 in 27,000 in fetal neoplasm [4]. 


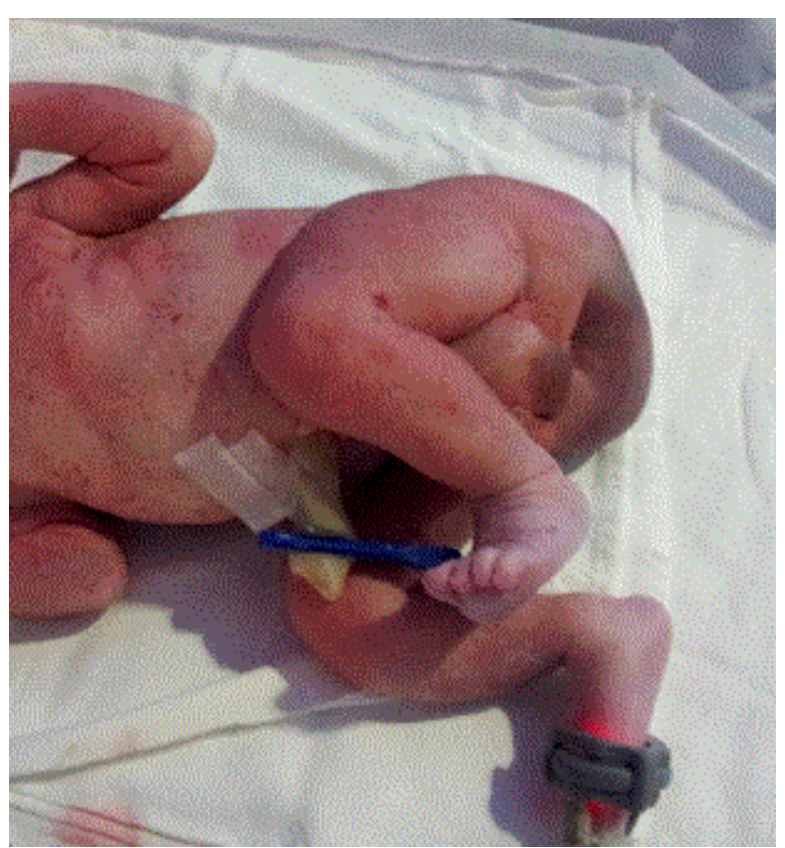

Figure 2: Figure showing swelling (mass) in Sacrococcygeal region which is about the size of $10^{\star} 12 \mathrm{~cm}$, solid and erythematous. Also note scrotal skin thickening with hydrocele.

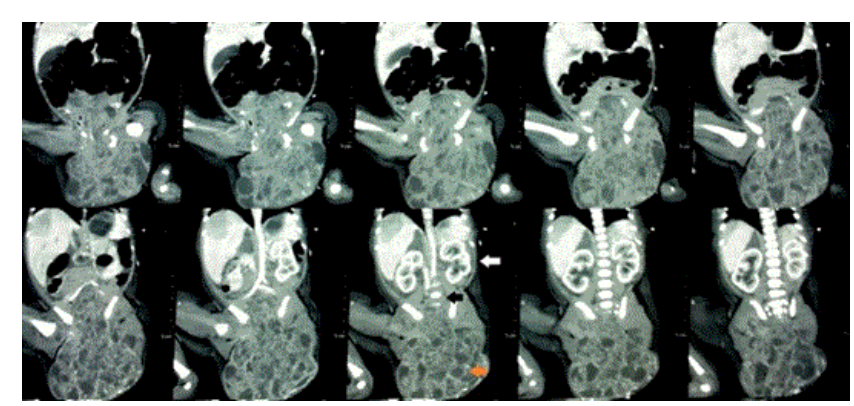

Figure 3: MRI scan of the baby showing intra-spinal extension of the sacrococcygeal teratoma.

Classification of SCT is based extent to which a tumor is external and/or internal and is given by American Academy of Paediatrics Surgical Section (APPSS) [5].

Type I-Predominantly external with minimal presacral component.

Type II-Present externally but with significant intrapelvic extension.

Type III-Apparent externally but predominantly a pelvic mass extending into the abdomen.

Type IV-Presacral with no external presentation.
Antenatally SCT causes polyhydramnios, hydrops fetalis, high cardiac output failure and prematurity. Postnatally, (type 3) teratoma may present as abdominal lump, and symptoms arising from compression of surrounding structures like urogenital or gastrointestinal systems etc. Antenatal diagnosis can be done by prenatal ultrasound where SCT appear as fluid filled cavity. Postnatally the neonate is investigated with CT scan or MRI to know about the extent and internal anatomy of the lesion $[6,7]$.

Differential diagnosis which are considered and can be differentiated on the basis of MRI, ultrasound and pathological examination includes Extraspinal ependymoma, Ependymoblastoma, Neuroblastoma, Rhabdomyosarcoma and Terminal myelocystocele $[8,9]$. Treatments of SCT that have spinal extension consist of complete resection of the tumor followed by close follow up. Post-operative complications include haemorrhage, bleeding, neurological deficit, bladder dysfunction and recurrence [10,11].

\section{Conclusion}

Sacrococcygeal tumor is the most common tumor diagnosed in fetus. SCT has been classified as four types based on weather tumor are external and/or internal. The spinal cord involvement of SCT is rare and management involves resection and close follow up.

\section{References}

1. Swamy R, Embleton N, Hale J (2008) Sacrococcygeal teratoma over two decades: birth prevalence, prenatal diagnosis and clinical outcomes. Prenat Diagn 28: 1048-1051.

2. Harms D, Zahn S, Göbel U, Schneider DT (2006) Pathology and molecular biology of teratomas in childhood and adolescence. Klin Padiatr 218: 296-302.

3. Audet IM, Goldhahn RT Jr., Dent TL (2000) Adult sacrococcygeal teratomas. Am Surg 66: 61 .

4. Huddart SN, Mann JR, Robinson K, Raafat F, Imeson J, et al. (2003) Sacrococcygeal teratomas: The UK Children's Cancer Study Group's experience. I. Neonatal. Pediatr Surg Int 19: 47-51.

5. Altman RP, Randolph JG, Lilly JR (1974) Sacrococcygeal teratoma. American Academy of Pediatrics Surgical Section survey-1973. J Pediatr Surg 9: 389-398.

6. Danzer E, Hubbard AM, Hedrick HL, Johnson MP, Wilson RD, et al. (2006) Diagnosis and characterization of fetal sacrococcygeal teratoma with prenatal MRI. AJR Am J Roentgenol 187: W350.

7. Roman AS, Monteagudo A, Timor-Tritsch I, Rebarber A (2004) Firsttrimester diagnosis of sacrococcygeal teratoma: The role of threedimensional ultrasound. Ultrasound Obstet Gynecol 23: 612-614.

8. Yu JA, Sohaey R, Kennedy AM, Selden NR (2007) Terminal myelocystocele and sacrococcygeal teratoma: A comparison of fetal ultrasound presentation and perinatal risk. AJNR Am J Neuroradiol 28: 1058-1060.

9. Santi M, Bulas D, Fasano R, Ponsky T, Sandler A, et al. (2008) Congenital ependymoblastoma arising in the sacrococcygeal soft tissue: A case study. Clin Neuropathol 27: 78-82.

10. Jelin E, Jelin AC, Lee H (2009) Sacrococcygeal teratoma with spinal canal invasion prenatally diagnosed. J Pediatr Surg 44: E9-11.

11. Shahjouei S, Hanaei S, Nejat F, Monajemzadeh M, Khashab ME (2015) Sacrococcygeal teratoma with intradural extension: Case report. J Neurosurg Pediatr 15: 380-383. 